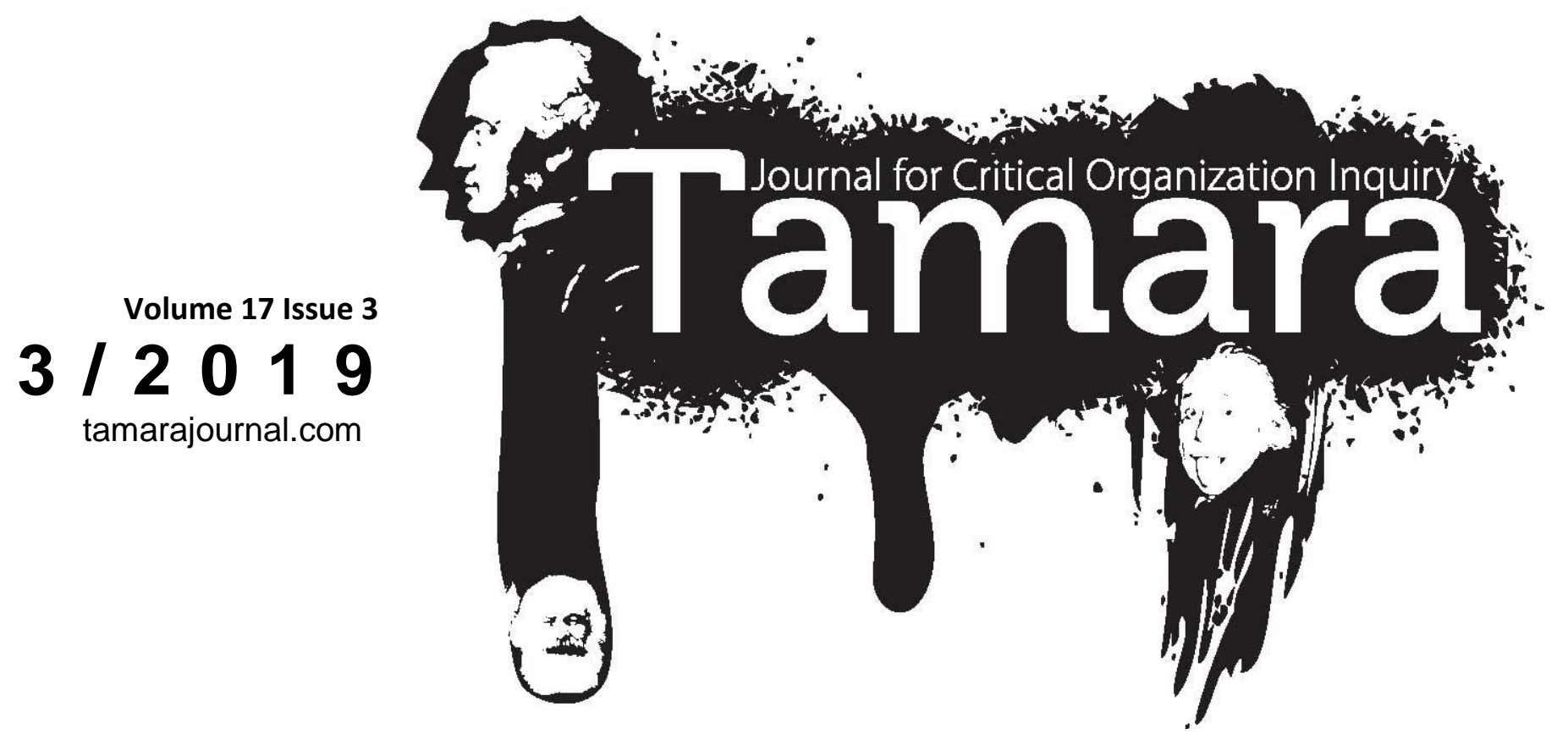

\title{
Managing for the common good: The case of Soplicex ${ }^{i}$
}

Aleksander Chrostowski

Kozminski University, Poland

Monika Kostera

The Jagiellonian University, Poland

Södertörn University, Sweden

\section{Keywords}

common good

action research

Poland

\begin{abstract}
The aim of this paper is to point to the potential value of an approach to management based on the idea of the common good, as opposed to classical capitalism based on private ownership. Such an approach makes it possible to resist a pursuit of short term oriented gains and a maximization of narrowly defined profits, and, instead, to focus on humanistic values, as to adopt a long term perspective. The much cited notion of the "tragedy of the commons" was based on deficient material and argumentation, but, most of all, it completely disregards of the issue of management. Using a case study developed through a longitudinal action research project in a big service enterprise we call "Soplicex", we present the strategic process grounded in learning, as well as the building of a strong structure centred on teams. The engagement of the employees was, originally, strongly oriented towards the idea of the common good. The consultants and researchers adopted this principle as the guiding rule in their work with the organization. Even though the process was interrupted by the takeover by a foreign investor, we show how the findings of the study remain relevant for alternative organizing and managing today and in the future. The conclusions of this paper reach further than just being reflections on a historical case study: a model of management is presented, concerned with the care and protection of the common good.
\end{abstract}

\section{A Romance of the Commons}

It seems to be a matter of common sense, or stark realism (Fisher, 2009), especially in today's Poland, that "real" property is private and everything else is either a mistake or a Utopia for the dinosaurs of communism. At the same time management has, presently, become almost exclusively focused on short term (see e.g. Bloom and Rhodes, 2018 for 
elaboration of causes and exploration of consequences), highly individualized, fragmented and almost exclusively financial aims, while disregarding from lager social and environmental concerns (Fleming, 2014, Parker, 2002; 2018). The common good has been relegated to the margins of organizational knowledge and practice (Fleming, 2019). However, such an approach is not representative either of the value or social and economic utility of the common. This article aims to remind of its importance and validity, as it presents a few reflections, based on case study material dating from over a decade ago, with a renewed relevance in today's turbulent world. Our aim is to present and illustrate an idea, not to inductively develop a grounded theory from empirical material. It is an abductive study, i.e. a pragmatic method in between deduction and induction, aimed at establishing relationships between field material and theory (Czarniawska, 1999). The empirical material consists of the authors' experience as participatory management consultants in the early 1990s and in particular illustrated by a case study developed through the adoption of action research methods under a period of 10 years in a large Polish service enterprise. The material is historical, but, following authors such as Roy Jacques (2006) and Tomasz Ochinowski (2013), associated with the so called historical turn in organization theory, we believe that the present can be understood and changed if we learn our historical lessons.

The contribution of this text is to show how the idea and practice of the common goodii in corporate management worked in its now historical context and to point to several implications for its possible future re-claiming and reintroduction in business management. This would need systemic changes of the context to take place, but we believe that such a shift may be necessary, if we are to ensure survival of the planet and human culture (with support of authors like Bauman, 2017 and Streeck, 2016). We consider the findings of our study as being part of the increasingly important area of organization theory focusing on alternative organizations, i.e. ideas, practices and forms of organizing outside of the management handbook mainstream (Parker, Fournier and Reedy, 2007). The framing of all management practices as defined by business or business-like crieria has strong ideological underpinnings and, even though the image of management as presented in today's business study programmes and in the media, is strongly biased toward it, as if it lacked any alternative, research shows that this is far from true.

\section{Organizing and the commons}

Michael Hardt's and Antonio Negri's well known book Commonwealth (2009) is devoted to a project to help humanity obtain - or, rather, regain - access to common goods, such as the goods of nature and culture. For the authors, modernity, which is usually presented as an advanced phase of progress, is, at its core, associated with capitalist exploitation and work alienation. In popular discourse, capitalism and modernity intertwine, are overpowering and inevitable. Capitalism is often presented as a force majeure, the only alternative to which is barbarism, and so, therefore no real alternative exists. Meanwhile, Hardt and Negri argue, joint solidarity and resistance can reveal the aspects of power that seems to cement capitalism in this way. Then and only then the exploitation can be opposed. It can be revealed that the assumption of the inevitability of capitalism is false. The question is not capitalism or regress; instead it is: a sustainable world of work outside capitalism or one characterized by capitalist alienation and oppression of barbaric proportions (Cederström and Fleming, 2012). There is an alternative - and there is an alternative management and organization model rooted in social movements and employee solidarity. Its central premise is the existence of the commons and the common good embraced as a leading value.

Similarly, the Polish-British architect and social scientist Krzysztof Nawratek (2012) understands the role of the common good as central in city planning, organization and management. In his opinion, the city should be a space of community, allowing institutions and residents for active participation, democracy, and the development of a sense of a common destiny. Urban change should not be brought about by the acquisition of more power, but through "understanding the mechanisms, which will allow restoration of the city's subjectivity and will regain the power to shape the city's own destiny and future" (ibid., p. 11). This can help to ensure a sustainable city in the future, instead of the currently rapidly progressing disempowerment, dispossession and exclusion, due to the capitalization of the city in terms of "built-up areas" ready for sale and investment. The city should be managed as a space for sociality, providing a context for emancipative change, innovation and creation. The city as a common good offers a collective agency and identity. In Nawratek's own words: 
I do believe that the essence of the city is that is self-manages and that the community not only inhabiting it but also using it should govern itself. But this community is much more than just a set labelled 'people' (ibid., p. 51).

Organizations of the common good, whether big or small, crave structures that lend identity, stability and enable responsible leadership. The common good does not mean the lack of management mechanisms. On the contrary, symbolic mechanisms and institutions are needed to order and give shape to democratic management methods and models. This knowledge does not have to be invented from scratch. The commons have a long and rich tradition - much can be learned from historical ideas and cases, including the ones which we are about to demonstrate.

The apparent dominance of the private and individualistic is temporary. Hardt and Negri (2009) note that capitalism has enthroned private property as its founding institution, and, at the same time, it was from the onset contesting the value of the common. Thinkers since the Enlightenment have been striving to argue in favour of this rationality, defending the republic of property, as well as values and attitudes supporting the private to the detriment of the common. The 1968 article titled "Tragedy of the commons" by American biologist Garrett Hardin is among the most commonly cited sources, and a bibliographic position with perpetual popularity (up to the date of the writing this text the original article has been cited 8367 times, according to the Web of Science database), and something of a shared anecdotal common knowledge. A World Bank discussion paper from 1989 calls it a discussion paradigm (in: Bromley and Cernea, 1989). It is said to offer conclusive proof that the common good inevitably leads to the impoverishment of the whole community sharing it. However, Hardin formulated his strong thesis based on a rather special case: the history of common pastures in the nineteenth-century England (the commons). Shepherds caused soil erosion, adding more animals to their herd, because it was profitable for them to do so. Every rational shepherd was acting in this way, thus contributing to the destruction of the commons. According to this logic, the rational individual maximizes his or her benefit at the expense of the common good. Meanwhile, several authors have since contested and refuted the thesis (see e.g. Bromley and Cernea, 1989; Ostrom, 1990; Angus, 2008; Anukwonke, 2015) Charles Anukwonke (2015) calls it a "pernicious myth", and argues that it has led to a worldwide justification of denigration the common, imposition private ownership and grabbing of land used by native and aboriginal cultures in developing countries. Bromley and Cernea (1989) declare that "the Hardin metaphor is not only socially and culturally simplistic, it is historically false" (p. 7). Hardin did not provide any scientific evidence to support his theses, just anecdotal narratives based on simplifications and largely out of context.

Furthermore, Hardin completely disregards from the central issue of management: the common good, such as common pastures, was historically managed and regulated by the community enjoying it, fully aware of the dangers posed by individual abuse. The rational shepherd was part of a rational system that cared to preserve the superior good in the condition for all beneficial. The English case invoked by Hardin was specific: there was an increasing struggle by rich farmers going on in the time he used in his description for the possibility of fencing off the land for private use. The strategy adopted by them was exactly as described by Hardin. It was a kind of wreckage economics, a reckless exploitation of the land to the detriment of the community. What Hardin described was the tragedy of the onset of capitalism, not the tragedy of the commons. It has nothing to do with "the nature of humankind" and everything to do with strategies of maximization of individual profit (egoism) at the cost of the greater whole (altruism). Furthermore, while proclaiming the inevitability of privatization, he did not offer any arguments that would convince the reader that by dividing up the common elements into private fragments, the devastation of the environment could be prevented (Angus, 2008). The popularity of this scientifically weak work can be explained by its ideological uses as a justification for privatization.

In contrast, Ellinor Ostrom (1990), awarded in 2009 the Nobel Memorial Prize in Economic Sciences for her work in the area, supported by convincing empirical evidence (collected in developing countries) and analysis of the material, argued that communities establish their own rules of managing common resources, including traditions, structures and cultural norms. She proposed that these institutions can be used, with much success, as organizing principles for managing systems which are neither market-driven nor centralized. The central issue is what is managed and how. The common good can be best supported by structures, mechanisms and systems rooted in community values. Then there is no need either for market forces or central planning. Management models of this kind look like mixtures of "private-like" and "public-like" institutions. These value based institutions make market ideologies and dogmas unnecessary. The latter are simplified and work for the benefit of the few. They need vast and extensive support system such as regulations and 
security. Institutions of the commons are both simpler and firmer, as they are based directly on other institutions working through culture and trust. Having said that, despite being "simple" in the sense of foundational support, the commons as organizing principle are very complex and do not exclude diversity, quite the contrary, they tend to thrive more in diverse social systems. Taking such historical and contemporary empirical arguments into consideration, Massimo De Nagelis and David Harvie (2014) argue for a "scholarly rehabilitation of the commons) (p. 284) as, indeed, ,the spectre of commonism may already be haunting the planet" (p. 292).

Against this background, we would like to present our case study of a medium sized service enterprise operating in Poland, based on an action research project conducted by one of the authors (initially with the second author's and other consultants' assistance) in the second half of the 1990s until the first years of the new millennium.

\section{Rise and fall of Soplicex}

This argument we are making here is not purely empirically driven and its aim is not the development of an inductive grounded theory. Rather, our aim is to present and illustrate the idea of the common good in the context of management of large organizations. The empirical study is abductive, focused on the establishing relationships between empirical material and theory (Czarniawska, 1999). Our argument builds on several empirical studies, one of which in particular serves as an illustrative vignette in the text. The central case study is based on material collected during 10 years by one of us. The second co-author assisted in the initial phase of the project, lasting 2 years, as participatory consultant (together with a larger team of co-consultants), while the first co-author carried out a full action research study from the onset to the completion of the process. The study was initiated in 1995 and lasted until 2005, with more intensive contact until 2003.

Action research is a methodology based on the idea of joint learning by the organization and the researcher. The latter supports and advises the organization, while, at the same time, he or she organizes the material and draws broader, theoretical conclusions from the processes in which he or she participates. We shall first present the methodology, as we believe it is, in itself, a good example of research based on notions of the common good, and also a useful model for strategic management, to be used in the management for the common good. Then we shall briefly narrate the case study of Soplicex from the perspective of the common (as different from private) good management. Finally in this section we will throw some light on the context of the story and its implications for managerial values and ideas.

\section{Action research}

Action research is usually traced back to William Foote Whyte's (1991) proposition of an approach to research which is simultaneously aimed to support communities and intended as a method for learning how to solve problems and overcome structural limitations. According to another of its founding fathers, Kurt Lewin (1948), action research is useful from a theoretical as well as practical point of view. It enables a systematic accumulation and comparison of different empirical cases in their wider context, which may serve as learning material for the use of social actors and theorists alike. Such an approach to research provokes and instigates social action and does not limit itself to producing publications.

Initially action research was conceived of as a kind of an experimental method utilized in real life context and not in a laboratory (Lewin, 1939). The action introduced was supposed to be an expression of a theory in such a way as to enable a direct relation to the adopted theory - the research. Later these experimental ambitions were abandoned or relaxed, to be replaced with an agenda focused on learning (Argyris and Schon, 1974). Whereas initially the role of theory and practice in action research were regarded as separate (or as consecutive phases), later, with the greater focus on learning, they have come to be seen as epistemologically different but interdependent and intertwined (Habermas, 1973). The researcher has to be equally open towards both sides. Ideally, action research should focus on concrete problems in a living context, and the diagnosis should embrace the entire system in its environment. Then problems are solved by means of learning and collaboration. The method is directly concerned with values, emancipation, change and high theoretical standards (Argyris, Putnam and Smith, 1985). This led to the recognition that both sides are equally important and should be realized simultaneously. Nowadays, action research is aimed at the creation of useful resources of knowledge resulting from research and, furthermore, at helping people who are involved in research, in order to gain a better understanding of the situation in which they are found, making it easier for them to solve their own problems (Morgan, 2001). It is also commonly agreed (see e.g. Greenwood and Levin, 1998) that there are no single or "best" solutions to be found through 
action research, but everything that emerges is evaluated by its value for the relationships between the researcher and the social actors, as well as whether it has succeeded in raising awareness.

Usually, action research is predominantly a qualitative methodology, composed of several methods, such as interview, observation, learning loops and hermeneutic methods (Whyte 1991; Greenwood and Levin, 1998). There should be an overarching research design, based on consecutive cycles of learning and development of practices. It is also imperative that all the participants (and not just the researcher) are engaged in the research process and that its main values are accepted by the social actors in the field (Rapoport, 1970).

In the presented case study all these conditions have been carefully considered and both the practical and the theoretical thrust have been given equal importance. The project had such double aims from the very beginning. It was collaborative and aimed at the empowerment and emancipation of the studied organization. Its success was measured in terms of the developing relationship. Multiple and mixed methods were adopted, mostly qualitative and ethnographically inspired, such as interview and observation, performative definition collection (standardized qualitative interviews, see e.g. Czarniawska-Joerges, 1992), but also quantitative such as surveys and measures of market performance ${ }^{\mathrm{iii}}$. There was a constantly emerging body of knowledge, which was used to improve practice and to develop a theoretical understanding. Most of the interviews were open and informal. The researcher took notes most of the time but recorded some of the interviews only on rare occasions. The research design was, as such, diverse and emergent, but it was persistently framed as an action research project, aimed at a (participative) diagnosis and solution of problems. Crucially, the study was conducted as a continuous, long-term learning endeavour, where the role of the researcher and the consultants was to support the employees and the management of the company in the development of a democratic and marketplace resilient strategy and operationalize it in the form of structures and procedures. The notion of the common good was not the objective of this process, it was neither taught nor instilled by management or the consultants. It was present when we entered, as it was present in all the other organizations, the experience from which forms the basis of the argument we present in this text.

The theoretical framing of action research can have radically different roots. Some studies are based on Marxist views on political economy and social transformation, others are rooted in pragmatic philosophy, yet others are built on the foundations of social psychology (Greenwood and Levin, 1998). This epistemological diversity is due to the fact that they are dealt with by practitioners and scholars with specializations within anthropology, education, engineering, psychology, organizational consulting, social welfare, sociology and many other fields (Deshler and Ewert 1995). The study presented in this text has its roots in the systems approach (Ackoff, 1999; Zawiślak, 1985), as well as an approach to learning, acknowledging its complexity and multi-layeredness (Argyris and Schön, 1985). The underpinning of the entire process was a profound respect for the studied organization and its participants, who were regarded as partners, rather than "research subjects" or "human resources". The process was both democratic and holistic, and the persons involved were concerned both about individual agency and dignity, and about the benefit of the organization seen as a system. A model that has been central for how the organization was conceived of was the classical Trist-Emery model (Trist and Emery, 1960), which regards the organizational system as a whole consisting of two probabilistic subsystems: people and goals, and two deterministic ones: structure and technology. Good management is about navigation and adaptation to the environment, using the assistance and cooperation of the probabilistic subsystems, while at the same time utilizing the deterministic subsystems to achieve stability and solidity over time.

Diversity is regarded as another important value for action research scholars (Greenwood and Levin 1998). Much attention is devoted to the diversity of human characters, needs and desires. Even in groups that appear very homogeneous, there are big differences in knowledge, interests, experience and abilities. In the theory of creating project teams, the diversity of competences, knowledge and preferred roles are highlighted as factors determining success in action. This is seen as vital in order to grasp the different areas, as well as to understand the everyday life of the community. In the presented case the participants of the organization were not characterized by a great diversity: they came from a similar ethnic and industrial background. However, there were some interesting differences among them, related to their different positions in the organizational hierarchy, difference in age, experience and education, as well as gender. These differences provoked many discussions, as well as some conflicts, but ultimately served as an inspiration to develop a broader model of co-determination for the practitioners and a deeper understanding of the organization and its problems for the researcher. 
The approach to action research used in the presented project can be described as a version of participatory action research (PAR). It is based on a particularly close collaboration and wide participation of people involved in the project (Whyte, 1991). There is a shared responsibility for both the diagnosis and the success of the endeavour, an honest approach to conflicts and differences in view and perspective and a dedication to communication on all stages of the project. The well-being of the organization and its participants was considered paramount. All other concerns, including the developing of theoretical understanding, were regarded as subservient to this fundamental aim.

\section{The story of Soplicex}

Soplicex was a large service company operating in the restaurant industry since the early 1990s. It was created as a daughter company of an even larger service organization with a history of over 50 years. At the time of our study it employed c:a 500 people, who had formerly been employees of the older mother company, and the workforce grew slightly each year. After the end of the project described here, it declined due to downsizing.

From the moment of making contact with the organization, both the authors had the impression that the employees and managers were particularly interested in something going far beyond improvement or development of management methods. This impression was strengthened throughout the years of cooperation. The initial request of the managers concerned support in the development of the company. They had then succeeded to avoid a takeover by a foreign investor which they deemed to be a "close call". In the beginning the acceptance of an investor had seemed to them as inevitable, even if not particularly attractive. They were aware of their company being less than a paragon of the virtues of competitive excellence. They were also aware of the risks of a takeover but did not see how they could possibly avoid it. However, after taking a good look at the investor's plans connected with the acquisition, they realized the full gravity of the situation. It would mean an almost complete replacement of their own structures and procedures with those of the investor. It would signify a gain in competitive position at the price of a loss of identity and autonomy. They backed out if the deal in the last minute, but felt an urge to do something about the organization's relatively weakening market position. This was where the participant consultants came in: they were invited as researchers and teachers whose task it was to help Soplicex to adapt to the requirements of an increasingly demanding market without sacrificing who they were and what the organization was and stood for. From the very beginning, the employees were involved in the processes. One of the most strongly formulated conditions was that none of the employees should be laid off due to the consulting process. And so the journey began.

The consultants called to a strategic session, with the participation of representatives of all employee groups and levels of the organizational structure, including representatives of all trade unions. The participants jointly discussed the current and possible future goals of the organization. Together with the researchers, they developed a new inclusive strategy. Responsibility was delegated to teams, that also acquired the necessary authority to manage tasks and areas they were responsible for. The tasks of the teams were very well defined, as to avoid discussions and ambiguities at the operative level. All strategic decisions would be made with the participation of a wide representation of the staff, and then there would be generous space for discussion, joint learning and conflict moderation. This structure called for well-defined procedures. Several sessions were dedicated to following processes and mapping them, so that they could be structured into working procedures. The knowledge and experience of key employees was to become an organic part of the management process. This was a major step towards self-management and self-organization based on empowered work teams. The consultants did not teach or train people to be oriented towards the common good: on the contrary, they followed their lead and basic concern about the commons, and derived their strategic solutions and propositions from that broad frame of reference.

Management recognized that a realistic and far-sighted strategy can be created and implemented if it emerges in the process of collective co-creation and joint responsibility. The extensive rights of the teams were formally included in the new structure. Human resource management, and especially evaluation and remuneration systems, were adapted to the team based structure. Managers at all levels were required to extensively consult the teams before any major decision was taken. Teams were also to support a systems thinking in the organization, assuming active participation and an empowered role in the strategy aimed at the achieving of common goals. In the words of an interviewee, people now 
[c]ould define their place, the scope of their competences, their responsibility - they could see and feel it (Manager 1).

The interviewees stressed that the new management system has released a huge potential in people, they felt much more free but also equipped with a great responsibility. Team evaluation eliminated the fear of making a mistake, and, at the same time, supported a greater concern with innovation, as well as accountability before the organization as a whole and other employees. The feeling of a shared responsibility combined with less anxiety gave people a feeling of comfort albeit without complacence. The new strategy together with the new rules for collaborative work made learning one of the basic rules of interaction with the environment. According to an interviewee the changes activated a huge potential in people:

The change in the company's mindset proved a great thing. The change in the rules of cooperation, a wonderful school of communication, a wonderful way of introducing a new philosophy in which the company is treated as a coherent organism, where everyone, regardless of his or her position, has a common aim. Thinking from the perspective of the product that will ultimately be judged by the client shows the real purpose of the company's multiple functions and posts. We succeeded in making people see their place in the organization, understand their problems and shortcomings and cooperate - I believe it is a great success (Manager 2).

A plan to develop employee participation in the ownership of the company was prepared. The staff reacted enthusiastically toward the proposition, but, contrary to an external commentator's remark, felt it was a natural step for the organization and not any unexpected "novelty". During the entire period of the action researcher's involvement the company had very good economic results and constantly achieved the highest ratings in terms of customer satisfaction.

The employees gained knowledge about management and several people from all hierarchical levels emphasized that this made them feel more confident.

I consider the theoretical knowledge in management the most important gain, these no-lecture-lectures, not really lecture but, rather, an introduction to what it is about. I really liked the theoretical underpinnings, it was great, because people got to realize something, specific and practical, but shown in a wide context of what it could be compared with, other cases, other ideas (Employee 1).

People gained confidence and felt an agency in their role as participants and co-organizers engaged in increasingly democratic management process:

[people] started to get into these processes, daring more, they begun to solve problems, they have now ideas of their own, even if things happen elsewhere, they see, they understand what's going on more, in a practical and a procedural sense. There is no longer the assumption that you have to ask permission from the top to do anything. So the skills how to solve problems are with the teams, the teams deal with things (Employee 2).

Indeed, collaboration itself was now regarded as an important skill, as important as individual knowledge and ability.

People have learned that it is not enough to do something by themselves, because the effect of their work can vanish, be ignored by others who may not understand why it's been done [... it's more important to work with others, in teams (Employee 3)

Things were developing in the direction of collaborative and participative management systems, which suited the participants well (according to evaluations) and the market reacted positively too, with the company growing more profitable and gaining a larger market share. However, eventually, there emerged on the scene some much more powerful forces, which neither the researcher nor the managers were able to deal with, and the company was, in the end, taken over by a foreign investor (albeit not the initial one). Its collaborative structures were dismantled, the self-managing teams 
abolished and the managers were dismissed (some left on their own initiative). The action researcher also disengaged himself from the collaboration and instead dedicated his time to interpreting and making sense of the collected material.

The action research process, as depicted above, reads not unlike a tale of an Arcadia lost, reminding us of Adam Mickiewicz's (1917) famous depiction of the village of Soplicowo from before the Russian occupation of the late $18^{\text {th }}$ century. But there were of course also problems and frustrations. The greatest of them all was the way that the story ends: the common good is abolished and the company re-shaped to function as any other neoliberal capitalist corporation. Compared with that, all else seems like perpetual bliss. But it should be remembered that the action research process itself is often arduous and testing. In the case of this project, the most trying aspect was the amount of time that everything took. The sessions often appeared to be endless, the time it took to agree on something and make a decision seemed to have no limit, and so on. The consultants were often exhausted and even the researcher, who knew very well that this was a rather regular feature of action research, could at times feel frustration, especially when something had been agreed upon but the decision was later disputed or the topic came up for discussion when he thought at least that point on the agenda has been dealt with. In the initial phase it was not unusual for some of the managers to call on the researcher's private phone, at all times of day, to discuss something that came up. There were also many intensive private and semi-private meetings between the social actors and the consultants in different configurations. It was at times difficult to work out which of the topics were, indeed, more private and which were formal discussion themes to keep in mind later at the session as something that "already has been addressed".

\section{Understanding the case in a context}

There is not much space in mainstream discourse, scientific, technical, practical or in media, for the upholding of the values of the common good, the commons regarded as a higher value. This lack and the predominance of an egoistic rationality are treated as something obvious, almost as a given of "human nature". However, our case shows that this is neither obvious, not inevitable, rather, it is part of a much more powerful process that has been going on in the context at the time that the project has been carried out. At the end of the 1980s and at the beginning of the 1990s, we have, together with our colleagues, engaged in a number of democratic consultancy projects of companies managed in ways not unlike the one described here. The aim of the consultants was to develop a strategy, and also at these occasions representatives of all levels of organizational structures and trade unions participated in the endeavour. The voice of management was final, but the scenarios were prepared on the basis of a deeply democratic process and knowledge retrieved at all levels of the organization, from worker to top management. The projects lasted for several years and included field research, such as semi-open interviews with representatives of all groups of employees. The attitude of the employees towards their organizations was, for us, very moving. These were their companies. They talked about them with much dedication and engagement, not only declarative under formal occasions, but also during informal chats. We experienced it as genuine and intensive engagement: we often saw people acting upon their value systems, such as resigning from immediate private gains for the sake of a greater common in the future. For example, at Soplicex people decided to forfeit seasonal bonuses and instead re-invest the funds into a new technology. Our company was, to the employees of these organizations, something that represented a shared higher value. They assumed that self-interest should be subjugated to what was regarded as common aims. Workers and directors alike, the old and the young, knew the history of their organizations and narrated it on various occasions, often personifying the company and magnifying the heroic qualities. There was a running plot oftentimes to be found in these stories: Our company has been through a lot, bad times and good times, and so, now we have to do everything we can to help get it get through the turbulent era ahead.

However, the transition towards a market economy of the 1990s did not favour this kind of engagement, value systems or management models based on them. The new discourse was from the start so strong it was overwhelming. It was supported by the media, education on all levels, practitioner organizations and other institutions. During that time one of us was conducting ethnographic research of Polish managers (Kostera, 1996). The study included media discourse and its changes during different eras. The study was partly retrospective, as it went back to the early times of state communism in Poland, as partly prospective, following the media images of the transition period. The results from the early 1990s were striking indeed: the image that emerged from the research was starkly black and white, without nuances (Kostera, 1996). Everything Western in management was good, modern and effective. Polish managers and organizations were depicted as ancient, of poor quality, outmoded, ineffective, boring. Such a blatant dualist approach did not serve learning of "new 
ways" of managing: learning requires thinking with scenarios, different problems and it is especially advantageous to present what Karl Weick, Kathleen Sutcliffe and David Obstfeld (1999) call near miss stories: cases in-between, of endeavours and situations there are not perfect but not a disaster either. An image of management as a story of "the prince and the beggar" was actually rather useless as learning material. Field research soon helped to throw some light on this mystery: teaching and learning was nearly not as important, as was ideology. Polish enterprises were to be privatized regardless of the wishes of their managers and employees, it was part of the so called Balcerowicz plan.

The second co-author also engaged in the ethnography of Polish managers in the time of the "transition" has heard such statements many times during her fieldwork, from the mouths of Polish and foreign consultants, and from the managers, too, albeit usually pronounced with bitterness, regret or a fatalistic resignation. They were subjected to a kind of intensive re-schooling propaganda, often labelled "management training" - and never mind that they were often highly qualified professionals who knew their job very well indeed. Some of the Polish pre-1989 managers held degrees in business administration, economics or organization and management. It happened that they graduated from good, high quality educational programmes, also from Western higher education institutions. They were, however, not asked about their educational needs by the Western consultants who came to Poland to "teach them management", but presented with a body of knowledge consisting either of platitudes and things they knew already or highly ideological contents. The results on a study dedicated to this training were published under the title "The modern crusade: The missionaries of management come to Eastern Europe" (Kostera, 1995). The first co-author, conducting action research, had similar experiences and recalls a situation when the "trainees" were so competent that the Western highly paid "trainers" aborted the deliverance of the module, as if out of pure shame. Instead, they began narrating different interesting cases studies from their consultancy experience to the Polish managers and discussing their implications.

During the ethnographic study the second co-author sometimes observed conversations between the consultants and the Polish managers. More than once the managers expressed a view that Polish companies can, at best, become subcontractors for Western corporations. They believed that they had to get rid of unnecessary "luggage", such as workers' councils and trade unions. The Western advisers did not say anything about subcontracting. Probably many of them knew already that the goal was indeed to prepare the Polish companies for a takeover by investors, only to be sold off further after a time of asset stripping or complete structural and cultural makeover. The "private is best" discourse was aimed at the demolishment of an existing value system where the common good played an important role. The first co-author recalls similar experiences from his projects. He also remembers the discussions held with the practitioners about the utter ineptitude of the new system to deal with what they called "immaterial value", that is the relations between the organization and the employees as well as the ethos held by the participants of the most fortunate enterprises. Cutting costs meant wasting all this, demolishing intrinsic motivation, shared responsibility and relationships that had taken decades to develop. The first co-author was once told by one of the managers: "Now, when I go to work, put on my coat, put on my mask no. 5 and only then leave home. I'm afraid I may, someday, forget about the mask..." The Polish "transition" has eliminated sincerity and heart-felt engagement from the relationship to work and the employing organization. It replaced them with competition, "entrepreneurship", grandiosity and rivalry. It is our view that these are the most visible consequences of the abolishment of the common good.

So all was privatized in the end, and the common good was forgotten about by the popular discourse and social memory. But does it mean that it had to be so? That is has to be so? And there is no alternative? We do not think so.

\section{Coda: At least we tried}

"I tried didn't I, Goddammit, at least I did that" says Randle McMurphy in One flew over cuckoo's nest (Forman, 1976) after his failed attempt to dislocate a heavy piece of equipment which, he hoped, would enable him and his copatients of a psychiatry ward to escape. The ward is run by a tyrannical nurse, sister Ratched, who terrorizes and intimidates the inmates. McMurphy is a crook and a wretched criminal but he knows, unlike the others, that there is another world out there and he does not cease hoping that he will one day be free. This is his secret way that enables him to keep his dignity even under the most despicable circumstances. His attempt to lift the heavy hydrotherapy cart and break out of the ward is not successful and the story does not end well for him. However, another of the patients, McMurphy's friend "Chief" later tries and succeeds to lift it and to escape from the hospital.

Similarly, we believe that, even though, the project of strategic stabilization of democratic management model in Soplicex failed then and there, the knowledge gained from it may be useful in another time, as a grounded idea for a 
change in a new context. The main organizing principle of the organization as common good was fundamentally important to the employees. It may, in altered systemic conditions, once again become useful as key impulse for organizing. Organization seen as common good is not necessarily pure communism or tribal Utopia. It does not mean lack of hierarchy or procedures. It means that the participants' and stakeholders' attitudes and values are subordinated to an organizing principle that acknowledges sharing and participation, including (striving for) collective ownership. This is also the foundation for the structuring of elements of organizations, such as: roles, positions, rights and responsibilities. The common good organization can be a modern service company, a cooperative shop or a university. As a principle of organizing and groundwork for participation it can be structured and implemented in various ways. There is place for the pursuing of this inquiry in contemporary management and organization theory as part of the increasingly popular research interest in alternative organizations. There is much related research available, to list just a few examples: Erik Olin Wright (2010) offers broad typology of organizations offers a perspective on organizing beyond the capitalist business frame as sustainable and effective alternatives. J.K. Gibson-Graham, Jenny Cameron and Stephen Healy (2013) provide a comprehensive guide for reframing the economy by organizing outside of the mainstream, from non-managerialist business, via property, to finance. Zofia Łapniewska proposes an alternative economic model of management based on the ethics of care (2017a) and the principle of the commons as a viable future path for the organization of urban (public) space (2017b). In this text we suggest adding to this extant knowledge research focused on the management of large production and service oriented organizations.

Such (and similar) alternatives have existed in the past, they exist now, and there may be an even more important role for them to play in the future. Ideas and experiences of alternative organizing may become a part of the process of creating a new model of the economy, or at the very least, they are here to stay and can be used as models and inspirations by practitioners and managers. This body of knowledge is, in itself a common good that can be used by many. The most important issue is that of shared agency, shared responsibility and sharing in the ownership. Otherwise the "common good" is less than "common". Employee stock ownership plans or full cooperative co-ownership are the main viable solutions. The employees should be treated like partners. It is important to realize that trust is difficult to gain, but easy to break and then very difficult to be regained again. Instead, a breach of trust is guaranteed to breed resentment and cynicism. As consultants active during the Polish transition towards market economy, we have witnessed and heard many sad stories confirming the sorrowful rule. Democratic structures of decision making and planning must be built upon existing customs and value systems in the region where the organization is operating. It is, of course, not necessarily obvious to establish which they are and how they can be of use in business management.

However, there are good ways of finding out. We would like to recommend action research as a suitable mode of establishing rules for management based on the principle of the commons and the common good. We have presented this participative methodology earlier in this paper. It respects the imperative not to impose, as change agents, "improvements", "innovations", or, indeed, any changes on an organization. Action research is a suitable and sustainable method to develop a relationship based on trust with all participants.

Finally, we would like to once again stress the role of management plays in the narrative of the common good. The cited literature points to its paramount importance. To conclude this text we would like to offer a brief summarizing recommendation of the key elements of management style relevant for the organization seen as common good with respect to its main areas. The action research study we have presented is based on a systems approach and several models and ideas, such as the mentioned Trist-Emery model (Emery and Trist, 1960) have been used as a framework during the process and later, to make sense of it. It is therefore natural for us to frame the implications as a Trist-Emery four-fielder (see table 1).

Management of/for the common good must be people oriented. The probabilistic subsystems have to be engaged in a constant process of dialogue, based on partnership and cooperation. Competitiveness needs to be reduced, so that attitudes such as jealousy and resentment, which may lead to dysfunctional treatment of the common good (rivalry, abuse, appropriation) are kept at bay. The goals need to be long-term oriented, not focused on growth and profit, but on sustainable survival of the organization. Goals and strategies are to be realized by learning and should be emergent, rather than pre-set. An excellent model to manage the goals subsystem is offered by the action research methodology: a participative and iterative process, guided by a researcher or a partnership oriented consultant. 
People: People the most important subsystem

- Co-responsibility

- Prospect of co-ownership

- Participation in decision making and planning

- Cooperation

- Non-competitive/ organismic culture
Structure: - adapted to local customs and conditions

- Allowing for co-determination

- If hierarchy then space for meetings over key strategic issues

- Teams with clear responsibilities

- Flat

- Low formalizations (but procedures exist)
Goals: - development of the common good while sustaining the community

- Long-term orientation

- Learning

- People and their competences at the heart of the strategy

- Emergent (diagnosis and adaptation, use of organization's strengths)
Technology: - supporting and not replacing work

- Part of learning process

- Procedures important

- Action Research

Table 1. Management for the common good organization: subsystems. Based on

Emery and Trist (1960).

The deterministic subsystems stabilize the organization seen as common good, firstly by the implementation of a structure which allows for co-determination and consultation, but where teams have a solid and well described responsibilities. The study we presented in this article shows that such teams are very good at diagnosing their areas of the organizations and proposing viable solutions. Finally, the management of an organization seen as common good needs to keep in mind the good of the participants and the adopted technology has to be fit for that purpose. It should help people to work, not replace them.

' Following a tradition in organizational ethnography, we have opted for letting our field and its actors remain anonymous. In order to protect their identity, we call the company Soplicex in this text, while, in reality, it had a different name. Soplicex is a pseudonym we invented using the name of a fictional village, Soplicowo, known from Adam Mickiewicz's famous epic poem Pan Tadeusz (English transl. 1917). The great Polish romantic poet envisaged the village as an almost Arcadian yet lively and complex country estate, irretrievably lost due to the Russian occupation after the partitions of Poland of the 18th century. We chose this name because of the romantic associations both it and our story evokes (on romanticism as the aura of the Polish management approach, see Średnicka, 2019), and because of an explicit reference to the poem during one of the sessions. After a particularly long an exhausting discussions one of the participants cited the title of the poem's last book: "Let us love one another!" (Mickiewicz, 1917), invoking a scene that at the same time inspires sadness of a past irrevocably lost and hope derived from the fact of being alive and able to tell the tale.

i We use the terms "commons" and "common good" interchangingly most of the time, with a preference for the latter when referring to organizations (the commons usually signifying larger contexts).

iii Not referred to in this text, however, there were 3 surveys comprising 31 to 79 responses.

\section{References}

Ackoff, R. L. (1999). Ackoff's Best: His classic writings on management. New York: Wiley.

Angus, I. (2008). The Myth of the Tragedy of the Commons. Climate and Capitalism, August 28, http://climateandcapitalism.com/?p=513

Anukwonke, C. (2015). The concept of the tragedy of the commons: Issues and applications, working paper, Uli:

Chukwuemeka Odumegwu Ojukwu University, retrieved from

https://www.researchgate.net/publication/277708953_The_Concept_of_Tragedy_of the_Commons_Issues_and_Appli $\underline{\text { cations }}$

Argyris, C., \& Schön, D. (1974). Theories in Practice. San Francisco: Jossey-Bass.

Argyris, C., Putnam, R., \& Smith, D.M. (1985). Action Science. San Francisco: Jossey-Bass. 
Bauman, Z. (2017). Retrotopia. London: Polity.

Bloom, P., \& Rhodes, C. (2018). CEO Society: The corporate takeover of everyday life. Winchester: ZED.

Bromley, D.W., \& Cernea, M.M. (1989). The management of common property natural resources : some conceptual and operational fallacies (English). World Bank discussion papers ; no. WDP 57. Washington, D.C. : The World Bank. http://documents.worldbank.org/curated/en/548811468740174575/The-management-of-common-property-naturalresources-some-conceptual-and-operational-fallacies

Cederström, C., \& Fleming, P. (2012). Dead man working. Winchester: Zero Books.

Chrostowski, A. (2006). Metoda Action Research w procesie doradztwa strategicznego. PhD thesis, Warszawa: Akademia Leona Koźmińskiego.

Chrostowski, A., \& Jemielniak, D. (2011). Skuteczne doradztwo strategiczne: Metoda Action Research w praktyce. Warszawa: Poltext.

Czarniawska-Joerges, B. (1992). Culture is the medium of life. In A. Sjögren \& L. Janson (Eds.), Culture and management in the field of ethnology and business administration. Stockholm: Invandrarministeriet, 15-29.

Czarniawska, B. (1999). Writing management: Organization theory as literary genre. Oxford: OUP.

De Angelis, M., \& Harvie, D. (2014). The Commons. In M. Parker, G. Cheney, V. Fournier \& C. Land (Eds.), The Routledge Companion to Alternative Organizations. Abington: Routledge, 280-294.

Deshler, D., \& Ewert, M. (1995). Participatory action research: Traditions and Major. London: SAGE.

Emery, F. E., \& Trist, E.L. (1960). Socio-Technical Systems. In C.W. Churchman \& M. Verhulst (Eds.), Management Science, Models and Techniques. London: Pergamon, 83-97.

Fisher, M. (2009). Capitalist Realism: Is there no alternative? Winchester: Zero Books.

Fleming, P. (2014). Resisting work the corporatization of life and its discontents. Philadelphia: Temple University Press. Fleming, P. (2019). Sugar daddy capitalism: The dark side of the new economy. Cambridge: Polity.

Forman, M. (1975). One flew over cuckoo's nest. United Artists.

Gibson-Graham, J.K., Cameron, J., \& Healy, S. (2013). Take back the economy: An ethical guide for transforming our communities. Minnaepolis: Minnesota University Press.

Greenwood, D.J., \& Levin, M. (1998). Introduction to action research. London: SAGE. Publications

Habermas, J. (1973). Theory and practice. London: Polity Press.

Hardin, G. (1968). The tragedy of the commons. Science, 162(3859), 1243-1248.

Hardt, M., \& Negri, A. (2009). Commonwealth. Boston: Harvard University Press.

Jacques, R.S. (2006). History, Historiography and Organization Studies: The Challenge and the Potential. Management \& Organizational History, 1(1), 31-49.

Kostera, M. (1995). The modern crusade: Missionaries of management come to Eastern Europe. Management Learning, 26(3), 331-352.

Kostera, M. (1996). Postmodernizm w zarzadzaniu. Warszawa: PWE.

Łapniewska, Z. (2017a). Etyka troski a gospodarka przyszłości. Praktyka Teoretyczna, 2(24), 101-122.

Łapniewska, Z. (2017b). (Re)claiming Space by Urban Commons. Review of Radical Political Economics, 49(1), 54-66. Lewin, K. (1939). Field theory and experiment in social psychology, concepts and methods. New York: Harper \& Row. Lewin, K . (1948). Resolving social conflicts. New York: Harper \& Row.

Mickiewicz, A. (1917). Pan Tadeusz, Or the last foray in Lithuania. (transl. George Noyes), Project Gutenberg, retrieved on 13.04.2019 from http://www.gutenberg.org/ebooks/28240?msg=welcome stranger

Morgan, G. (2001). Wyobraźnia organizacyjna. Warszawa: PWN.

Nawratek, K. (2012). Holes in the whole: Introduction to the urban revolutions. Winchester: ZED.

Ochinowski, T. (2013). Tradycje przedsiębiorczości w Polsce jako źródło kapitału kulturowego organizacji. Warszawa: WZUW.

Ostrom, E. (1990). Governing the commons: The evolution of institutions for collective action. Cambridge: Cambridge University Press.

Parker, M., Fournier, V, \& Reedy, P. (2007). The dictionary of alternatives. London: Zed Books.

Parker, M. (2002). Against management: Organization in the age of managerialism. Cambridge: Polity. 
Parker, M. (2018). Shut down the business school: What's wrong with management education. London: Pluto.

Rapoport, R.N. (1970). Three Dilemmas in Action Research. Human Relations, 23(6), 23-38.

Streeck, W. (2016). How will capitalism end? Essays on a failing system. London: Verso.

Średnicka, J. (2019). Organizacja, wspólnota, bunt. Jak mity romantyczne kształtują wspótpracę w przedsiębiorstwie czasów transformacji? Doctoral thesis, Kraków: Uniwersytet Jagielloński.

Weick, K.E., Sutcliffe, K.M., \& Obstfeld, D. (1999). Organizing for high reliability: Processes of collective mindfulness. In: R.S. Sutton \& B.M. Staw (Eds.) Research in Organizational Behavior, Volume 1, Stanford: Jai Press, 81-123. Whyte, W.F. (ed.) (1991). Participatory Action Research. New York: SAGE.

Wright, E.O. (2010). Envisioning real utopias. London: Verso.

Zawiślak, A.M. (ed.) (1985). System i metoda. Warszawa: Wydawnictwo UW. 